\title{
NEUROIMAGING IN AFEBRILE SEIZURE IN PAEDIATRIC AGE GROUP
}

\author{
Shantala Rajshekhar Koujalgi ${ }^{1}$, Ravi Kanth ${ }^{2}$
}

${ }^{1}$ Associate Professor, Department of Paediatrics, Bidar Institute of Medical Sciences, Bidar.

${ }^{2}$ Assistant Professor, Department of Paediatrics, Bidar Institute of Medical Sciences, Bidar.

\section{ABSTRACT}

\section{BACKGROUND}

Seizures are very common in paediatric age group due to immature neuronal arborisation. Many cases present to Casualty with convulsions due to various causes. This study is done to know the importance of Neuroimaging in afebrile seizures.

\section{MATERIALS AND METHODS}

It is an observational prospective study. This study is conducted in Department of Paediatrics, Bidar Institute of Medical Sciences, Bidar, for a period of 1 year from Jan 2016 to March 2017. During this period, 80 cases ( 6 months to 12 years' age group) of 1 st episode of afebrile seizure were studied. A thorough clinical and neurological examination was done for all 80 cases and basic investigation was done for all the cases, viz. CBP, ESR, Mantoux test, x-ray chest, EEG and CT scan was done for all 80 cases. Radioimaging (CT) and Mantoux test was done for all cases.

\section{RESULTS}

Out of total 80 cases majority cases of 1 st episode afebrile seizure, i.e. 60 cases (75\%) showed abnormal neuroimaging and 20 cases (25\%) showed normal neuroimaging. Of these 60 cases, 39 cases were NCC and 18 cases were tuberculoma followed by one each medulloblastoma, astrocytoma and porencephaly.

\section{CONCLUSION}

Based on these findings, neuroimaging should be performed in children with 1st episode of afebrile seizure in area with more cases of NCC and tuberculoma.

\section{KEYWORDS}

Seizures, NCC (Neurocysticercosis), NI (Neuroimaging), Tuberculoma and CT Scan.

HOW TO CITE THIS ARTICLE: Koujalgi SR, Kanth R. Neuroimaging in afebrile seizure in paediatric age group. J. Evolution Med. Dent. Sci. 2017;6(71):5075-5078, DOI: 10.14260/Jemds/2017/1103

\section{BACKGROUND}

Seizure is a neurological disorder affecting infants and children more frequently than in any other age group. In first 16 years of life, $4 \%$ - $10 \%$ of children suffer with at least one episode of seizure and out of the 3.1 million people develop seizure annually; $40 \%$ are younger than 15 years and more than $80 \%$ are in developing countries.(1)

Based on several studies, the prevalence of abnormal neuroimaging in paediatric patients with new-onset afebrile seizure is estimated to be $0 \%$ to $21 \%$.(2)

Seizure is defined as transient involuntary alteration of consciousness, behaviour, motor activity, sensation or autonomic function caused by an excessive rate and hypersynchrony of discharge from a group of cerebral neurons. Children with new onset of afebrile seizure coming to paediatrics department of BRIMS Hospital, Bidar, were evaluated. Cases were collected over a period of 1 year to know the abnormal neuroimaging in these group of children. There is lack of neuroimaging with $1^{\text {st }}$ episode of afebrile seizure.

Financial or Other, Competing Interest: None.

Submission 10-08-2017, Peer Review 25-08-2017,

Acceptance 28-08-2017, Published 04-09-2017.

Corresponding Author:

Dr. Ravi Kanth,

Q. No. 32/BRIMS. Staff Quarters,

BRIMS, Bidar.

E-mail: ravibilgundi@gmail.com,

shantalark@gmail.com

DOI: $10.14260 /$ jemds $/ 2017 / 1103$
In developing countries, the incidence of CNS infection are common in comparison to western world where the aetiological factors are different. Hence, neuroimaging can be considered for the $1^{\text {st }}$ episode of seizure in our country.

\section{Aim and Objective/ The Main Aim of this Study is-}

- To determine the frequency of abnormal imaging in children aged between 6 months to 12 years with newonset afebrile seizure in Paediatric Department, Bidar Institute of Medical Sciences, Bidar.

- $\quad$ Period of study: 1 year between Jan 2016 to March 2017.

- Type of study: It is observational prospective study.

\section{MATERIALS AND METHODS}

This study is conducted in Department of Paediatrics, Bidar Institute of Medical Sciences, Bidar for a period of 1 year from Jan 2016 to March 2017. During this period, 80 cases of $1^{\text {st }}$ episode of afebrile seizure was studied. Patient presenting with associated symptoms were headache, vomiting, loss of consciousness, deviation of angle of mouth, automation and postictal palsy.

All cases of $1^{\text {st }}$ episode of afebrile seizures were included. A thorough clinical and neurological examination was done for all 80 cases and basic investigation was done for all the cases, viz. CBP, ESR, Mantoux test, x-ray chest, EEG and CT scan was done for all 80 cases.

\section{Radioimaging and Mantoux Test was done for all Cases}

- Mantoux test was positive in 18 cases. All 18 cases had abnormal neuroimaging showing tuberculoma. 
- CT scan was done for all cases of study population. It was abnormal in 60 (75\%) and normal in $20(25 \%)$.

Ethical Committee of Bidar Institute of Medical Sciences, Bidar, has given the clearance certificate to conduct this study. Written consent was taken from all study cases by their parents or reliable attender.

\section{Statistical Analysis}

All the statistical analyses were performed by using SPSS-20 version and Excel-2007. Variable were reported as \pm 2 standard deviation; Chi-square test was performed to determine the correlation.

$P$ value of $<0.05$ was considered statistically significant.

\section{Inclusion Criteria}

All babies with $1^{\text {st }}$ episode of afebrile seizures are included in the study.

\section{Exclusion Criteria}

1. Baby's age group of $<6$ months and children $>12$ years are excluded.

2. Convulsion associated with fever are excluded.

3. Known case of seizure disorder are excluded.

\section{RESULTS}

A total of 80 Cases were presented with $1^{\text {st }}$ Episode of Unprovoked Afebrile Seizures-

- 18 cases were simple partial seizure (22\%), (SPS).

- 33 (41.3\%) were complex partial seizures, (CPS).

- 25 (31.3\%) were generalised seizures, (GTCS).

- $4(5 \%)$ partial seizures with secondary generalised seizure (Sec GTCS).

\begin{tabular}{|c|c|c|}
\hline Seizure Type & Frequency & Percent \\
\hline CPS & 33 & 41.3 \\
\hline GTCS & 25 & 31.3 \\
\hline Sec GTCS & 4 & 5 \\
\hline SPS & 18 & 22.5 \\
\hline Total & $\mathbf{8 0}$ & $\mathbf{1 0 0}$ \\
\hline \multicolumn{2}{|c|}{ Table 1. Distribution of Seizure Type } \\
\hline
\end{tabular}

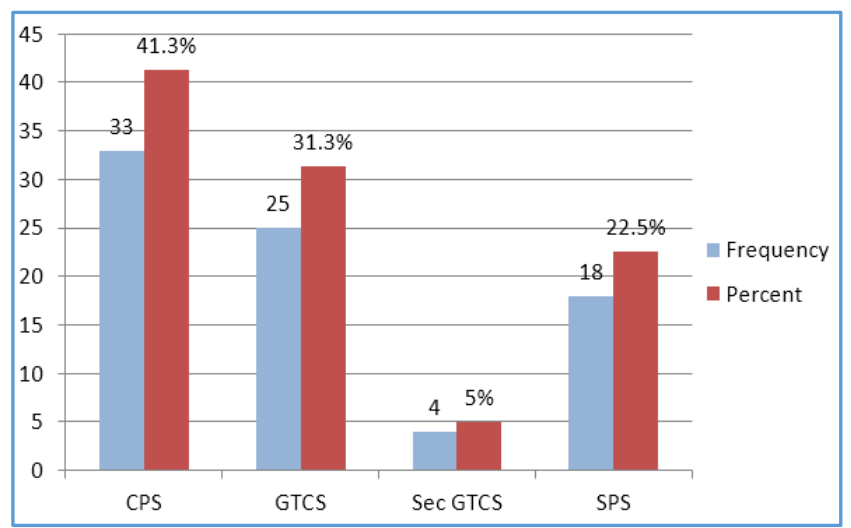

Distribution of Seizure Type

\begin{tabular}{|c|c|c|}
\hline Neuroimaging Findings & Frequency & Percent \\
\hline NCC & 39 & 48.8 \\
\hline Tuberculoma & 18 & 22.5 \\
\hline Astrocytoma & 1 & 1.3 \\
\hline Medulloblastoma & 1 & 1.3 \\
\hline Porencephaly & 1 & 1.3 \\
\hline Normal & 20 & 25 \\
\hline Total & 80 & 100 \\
\hline \multicolumn{3}{|c|}{ Table 2. Case shown in below } \\
\hline
\end{tabular}

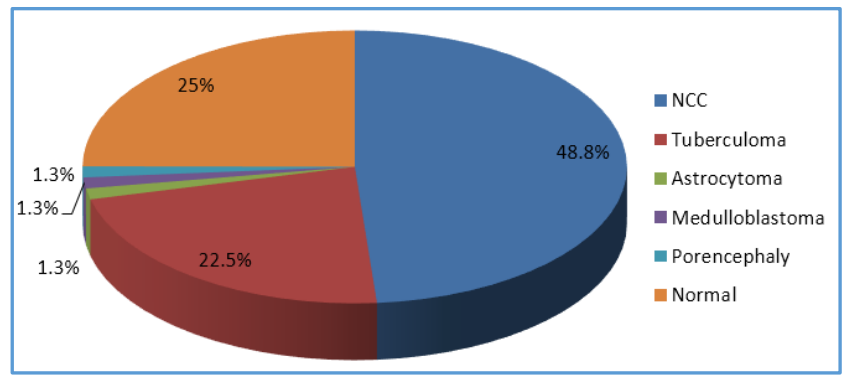

Neuroimaging Findings

NCC is the most common cause of abnormal neuroimaging in our study (39 cases- 48.8\%). Out of 60 abnormal neuroimaging 39 cases were NCC, 34 cases showed single lesion and 5 cases showed multiple lesions. Calcification was seen in 16 cases and 14 cases were noncalcified. Ring enhancement was seen in 18 cases of total 39 cases of NCC. Of total 39 cases of NCC, 32 cases gave history of pork eating and 7 cases were pure vegetarians. This showed that NCC can also be caused by faeco-oral contamination in pure vegetarian people.

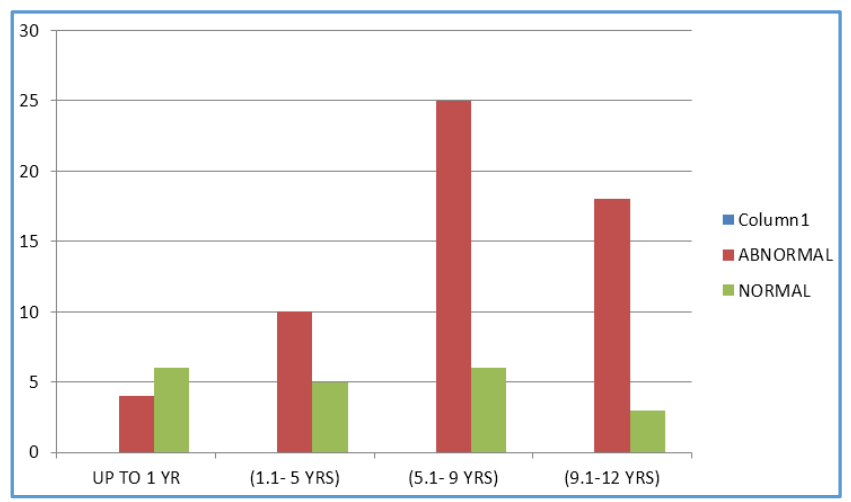

Age and Neuroimaging

Age

On comparing the age of presentation of neuroimaging abnormality, following observations were done. In this study 60 cases showed abnormal neuroimaging (75\%), in which highest number of abnormal neuroimaging is seen in $5-9$ years $(41.7 \%)$ followed by $9-12$ years of age (30\%). Significant correlation was seen between age and neuroimaging $(\mathrm{P}=<0.05)$. There were 51 cases of partial seizures, of which 37 cases (52.54\%) showed abnormal neuroimaging. There were 29 cases of generalised seizures and 23 cases showed abnormal neuroimaging. 
Tuberculoma is the next common cause of abnormal neuroimaging in our study out of total 60 cases of tuberculoma comprised of 18 cases (22.5\%). All cases of tuberculoma were Mantoux positive. This shows that there is a significant correlation between abnormal neuroimaging and Mantoux test $(\mathrm{P}=<0.05)$.

\begin{tabular}{|c|c|c|}
\hline \multirow{2}{*}{ Mantoux Test } & \multicolumn{2}{|c|}{ Neuroimaging } \\
\cline { 2 - 3 } & Abnormal & Normal \\
\hline Negative & 43 & 18 \\
\hline Positive & 18 & 02 \\
\hline Total & $\mathbf{6 0}$ & $\mathbf{2 0}$ \\
\hline
\end{tabular}

\section{DISCUSSION}

The prevalence of abnormal neuroimaging in several studies ranged between $0 \%-21 \%$. Practice parameters which have been recently published(2) recommend emergent neuroimaging to be performed in a child of any age, who exhibits a postictal focal deficit (Todd's paresis) not quickly resolving or who is not recovered to the preictal state within several hours after the seizure.

Afebrile seizure is a disorder occurring in the young. In our study, most patients i.e. $38.8 \%$ belong to age group of 5 9 years. These observations in accordance with other studies done including all age groups, which states that the majority of patients were below the age of 20 years. In our study, male sex (55\%) is more affected than female sex (45\%).

of 60 cases, abnormal neuroimaging in our study majority were NCC. Cysticercosis is a disease of low socioeconomic condition associated with poor hygiene and sanitation and poor safe drinking water. In a study conducted in Kerala, Kuruvilla, et $\mathrm{al}^{(3)}$ found that $73 \%$ patients belonged to low socioeconomic category. In similar two studies conducted from Chandigarh, $69 \%$ and $82.7 \%$ of the patients were of low socioeconomic strata. ${ }^{(4,5)}$ Majority $(72.5 \%)$ of the cases in our study were of lower socioeconomic class. Hence, our results are similar to other Indian studies.

In our study out of total 80 patients, (55) were taking non-vegetarian $(70 \%)$ and 32 gave a history of pork eating twice or thrice. There is a significant increase in ring enhancing lesions diagnosed as Neurocysticercosis in pork eaters $(58.1 \%)(\mathrm{P}=0.02)$. Many of our patients about 25 were pure vegetarians, $31 \%$ supporting the fact that faeco-oral contamination is also a major route of the disease transmission. In a previous study from Chandigarh, 53.2\% patients were reported as pure vegetarians. ${ }^{(6)}$

In our study, most of the patients had complex partial $(41.3 \%)$ followed by GTCS seizures $(31.3 \%)$ in concordance with the distribution described the International League against Epilepsy (ILAE) 2006. This is shown in Table-I.

In our study, commonest CT namely Neurocysticercosis 39 cases (49\%) and Tuberculoma 18 cases (23\%) comprising of total $57(71.2 \%)$ cases in our studies, which is comparative to $63.3 \%$ in other studies.

Most of the studies in India dealt with single lesion neurocysticercosis (solitary cysticercal granuloma). In our study, lesions were mainly single lesion i.e. 53\%, which is comparable with most of the Indian studies. A study by Kuruvilla et al(3) found single lesion in $40 \%$ and multiple lesions in $60 \%$ patients. Single lesion were present in $76 \%$ and multiple lesions in $24 \%$ patients in a study by Singhi et al.(7) Similarly Kotokey et al(8) reported single lesion in
$66.66 \%$ and multiple lesions in $33.33 \%$ patients, and Rajshekhar et al(9) reported single lesion in $60.88 \%$ and multiple lesions in $39.13 \%$ patients.

In our study $21(36 \%)$ of the lesions were situated in the parietal lobe, Baranwal et al and Singhi et al reported parietal lobe involvement in $41 \%$ and $57.3 \%$ patients respectively. $(4,5)$

Results of our study also shows a considerably higher proportion of neuroimaging abnormalities, which include various findings such as NCC, Tuberculoma, tumour and CNS malformations. This is shown in Table-II.

Most common neuroimaging abnormality observed was NCC (49\%) followed by tuberculoma (23\%), which are similar to Shipra Mathur et al(10) (2007), which was comparable with Sharma et al and Maytal et al's(11) studies.

Various confounding factors may have direct correlation with normal neuroimaging finding. In our study which includes low socioeconomic status, lower literacy rate, higher prevalence of tuberculosis and NCC poor hygiene and poor nutritional status.

In our study, $50 \%$ cases of generalised seizure and $83.8 \%$ cases of partial seizure have abnormal neuroimaging. Partial seizure abnormality was similar to those of George et al(12) (2006).

In our study, statistical significance was observed between Mantoux positivity and abnormal neuroimaging $(\mathrm{P}<$ 0.05). D. Vijayasekaran et al(13) (2006) showed that $21.2 \%$ Mantoux test and $30.4 \%$ contact positivity were found in CNS tuberculoma.

Seizures due to NCC are increasingly reported from India. Wadia et al observed that $26 \%$ of patients with partial seizures showed NCC lesions and the rate was higher among children, as $40 \%$ of his patients were below 15 years.

\section{Recommendations}

Incidence of neuroimaging abnormality in children presenting with first afebrile seizure is high in developing countries like India due to the high prevalence of neurocysticercosis and tuberculosis. So neuroimaging should be considered in any child with first episode of afebrile seizure.

Though CT scan is easily available and cost effective, MRI would be more specific, superior and more sensitive neuroimaging modality.

MRI permits localisations of lesion, defines scolex in lesion clearly and reveals more precisely the stage of evolution of lesion and type of cysticerci present ${ }^{(14,15)}$ and no radiation.

\section{CONCLUSION}

The commonest CT abnormalities are neurogranulomas, namely neurocysticercosis (49\%) and tuberculoma (23\%) were seen in $57(71.2 \%)$ cases in our studies comparative to $63.3 \%$ in other studies.

Although cysticercosis incidence is greater in pork eaters, faeco-oral route is also a major route of disease transmission and may also occur in population not eating pork. Cysticercosis is also more common in low socioeconomic status, poor hygiene and sanitation conditions which is evident in this study.

A very good correlation between abnormal neuroimaging with age and seizure type, abnormal neuroimaging with $\mathrm{H} / \mathrm{O}$ 
pork eating and abnormal neuroimaging with Mantoux test $(\mathrm{P}=0.05)$ was observed.

Prolonged Seizure activity, Age, Focal Seizures, Pork eating, Mantoux test

These are predictors of abnormal finding on Neuroimaging in Paediatric afebrile seizure cases.

\section{REFERENCES}

[1] Landfish N, Gieon-Korthals M, Weibley RE, et al. New onset childhood seizures. Emergency department experience. J Fla Med Assoc 1992;79(10):679-700.

[2] Hirtz D, Ashwal S, Berg A, et al. Practice parameter: evaluation of a first nonfebrile seizure in children: report of the quality standard subcommittee of the American academy of neurology, the child neurology and the American epilepsy society. Neurology 2000;55(5):616-23.

[3] Kuruvilla A, Pandian JD, Nair M, et al. Neurocysticercosis: a clinical and radiological appraisal from Kerala state, South India. Singapore Med J 2001;42(7):297-303.

[4] Baranwal AK, Singhi PD, Khandelwal N, et al. Albendazole therapy in children with focal seizures and single small enhancing computerized tomographic lesions: a randomized, placebo controlled, double blind trial. Pediatr Infect Dis J 1998;17(8):696-700.

[5] Singhi P, Dayal D, Khandewal N. One week versus four weeks of albendazole therapy for neurocysticercosis in children: a randomized, placebo-controlled double blind trial. Pedi Infect Dis J 2003;22(3):268-72.

[6] Das RR, Jain S, Maheshwari MC. Neurocysticercosis: an analysis of 206 cases from an Indian hospital. Ann Ind Acad Neurol 2001;4(2):95-8.
[7] Singhi P, Ray M, Singhi S, et al. Clinical spectrum of 500 children with neurocysticercosis and response to albendazole therapy. J child Neurol 2000;15(4):20713.

[8] Kotokey RK, Lynrah KG, De A. A clinic-serological study of neurocysticercosis in patients with ring enhancing lesions in CT scan of brain. J Assoc Physicians India 2006;54:366-70.

[9] Rajshekhar V, Raghava MV, Prabhakaran V, et al. Active epilepsy as an index of burden of neurocysticercosis in Vellore district, India. Neurology 2006;67(12):2135-9.

[10] Mathur S, Southern K, Sharma M. Significant findings on cranial CT scan after a first unprovoked seizure in children from North India. J Trop Pediatr 2007;53(6):428-30.

[11] Maytal J, Krauss JM, Novak G, et al. The role of brain computed tomography in evaluating children with new onset of seizures in the emergency department. Epilepsia 2000;41(8):950-4.

[12] Swingler GH, Westwood AT, lloni K. The utility of computed tomography for recent-onset partial seizures in childhood. S Afr Med J 2006;96(9 Pt 2):941-4.

[13] Vijayasekaran D, Kumar RA. Mantoux and contact positivity in tuberculosis. IJP 2006;73:989-93.

[14] Garg RK, Nag D. Single ring or disc enhancing CT lesion in Indian children and adolescents after single seizures. Arch Pediatr Adolesc Med 1997;151(6): 632-4.

[15] Garcia HH, Del Brutto OH, Nash TE, et al. New concepts in the diagnosis and management of neurocyticercosis. Am J Trop Med Hyg 2005;72(1):3-9. 